\title{
A Broadband Balanced Distributed Frequency Doubler With a Sharing Collector Line
}

\author{
Kun-You Lin, Member, IEEE, Jhih-Yu Huang, Student Member, IEEE, Chi-Kai Hsieh, and Shih-Chieh Shin
}

\begin{abstract}
A broadband balanced distributed frequency doubler fabricated by $0.35 \mu \mathrm{m}$ SiGe BiCMOS technology is developed to operate from 4 to $18 \mathrm{GHz}$ output frequency. This balanced doubler consists of an active balun and a distributed doubler. A sharing collector line is used in the balanced distributed doubler to reduce the chip size. This circuit exhibits a measured conversion loss of less than $8 \mathrm{~dB}$ and a fundamental rejection of better than $23 \mathrm{~dB}$ for the output frequency between 4 and $18 \mathrm{GHz}$. The chip size is $1.1 \times 0.7 \mathrm{~mm}^{2}$.
\end{abstract}

Index Terms-Balanced doubler, distributed doubler, SiGe BiCMOS.

\section{INTRODUCTION}

$\mathbf{R}$ ECENTLY, the strong demand for high-speed wireless communication systems requires broadband and high-quality frequency sources. An oscillator cascaded with a frequency multiplier can relax the requirements of the local oscillation (LO) source. Therefore, broadband frequency multipliers are the important components in high-speed wireless communication systems.

Broadband frequency doublers can be implemented by distributed topology [1]-[3]. In order to achieve a good fundamental rejection, distributed doublers with a high-pass drain line were proposed, however, the operation bandwidth is limited due to the output high-pass filter [1], [2]. The balanced structure can also be applied to design a broadband frequency doubler with a good fundamental rejection. A GaAs HEMT balanced distributed doubler that consists of a reduced size rat-race coupler and two identical distributed doublers demonstrated a conversion gain between -3 and $-6 \mathrm{~dB}$ from 30 to $50 \mathrm{GHz}$ output frequency, but it requires a $10 \mathrm{dBm}$ input power and $132 \mathrm{~mW}$ dc power [3]. An InGaP heterojunction bipolar transistor (HBT) balanced doubler with active balun has a $10 \mathrm{~dB}$ average conversion gain between 14 to $24 \mathrm{GHz}$ output frequency and consumes $200 \mathrm{~mW}$ dc power [4]. The Gilbert-cell topology is also suitable for the balanced doublers [5], [6]. A dc to $86 \mathrm{GHz}$ InP DHBT doubler presents a conversion gain between -3 and

Manuscript received July 20, 2008; revised November 13, 2008. Current version published February 11, 2009. This work was supported in part by the National Science Council of Taiwan under Grant NSC 96-2219-E-002-019, by Excellent Research Projects of National Taiwan University, under 97R0062-03, and by TSMC through the Chip Implementation Center (CIC), Taiwan.

The authors are with the Department of Electrical Engineering and Graduate Institute of Communication Engineering, National Taiwan University, Taipei 106, Taiwan (e-mail: kunyou@ntu.edu.tw).

Color versions of one or more of the figures in this letter are available online at http://ieeexplore.iee.org.

Digital Object Identifier 10.1109/LMWC.2008.2011336

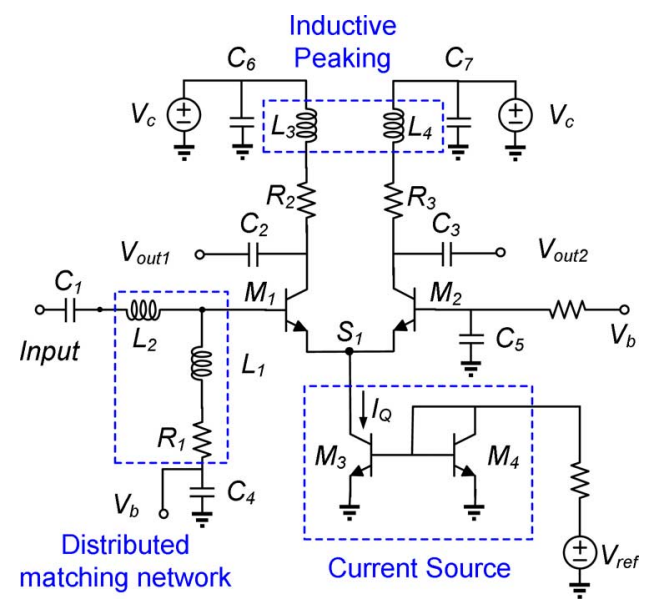

Fig. 1. Schematic of the active balun.

$-6 \mathrm{~dB}$ and consumes $730 \mathrm{~mW}$ dc power [6]. Most of the previously reported broadband balanced frequency doublers require high power consumption.

In this letter, a broadband balanced distributed doubler with active balun is developed by using TSMC $0.35 \mu \mathrm{m} \mathrm{SiGe}$ BiCMOS technology. The distributed doubler with two identical base lines and a sharing collector line is proposed to reduce the chip size. This doubler has a conversion gain better than $-8 \mathrm{~dB}$ and the fundamental rejection is better than $23 \mathrm{~dB}$ from 4 to $18 \mathrm{GHz}$. The dc power consumption is $54 \mathrm{~mW}$, and the chip size is $1.1 \times 0.7 \mathrm{~mm}^{2}$. This doubler demonstrates broadband characteristic and good fundamental rejection under a lower dc power consumption compared with other balanced frequency doublers.

\section{Circuit Design}

This circuit is fabricated by $0.35 \mu \mathrm{m} \mathrm{SiGe} \mathrm{BiCMOS} \mathrm{process.}$ This process provides three poly layers for the emitter and base of the SiGe HBTs and the gate of the CMOS transistors and three metal layers for interconnections. The HBT in this process has a $f_{T}$ of $70 \mathrm{GHz}$ and a $f_{\max }$ of $57 \mathrm{GHz}$. The MIM capacitor of $1 \mathrm{fF} / \mu \mathrm{m}^{2}$ capacitance is also available in this technology.

The balanced distributed doubler is composed of an active balun and a distributed doubler. Fig. 1 shows the schematic of the active balun. The single-ended input signal is divided into two signals with equal magnitude and $180^{\circ}$ phase difference by the active balun, and these two signals are fed to the transistors of the distributed doubler to generate the harmonic signals. The fundamental signals are cancelled and the second harmonic signals are in-phase combined at the output of the doubler. 


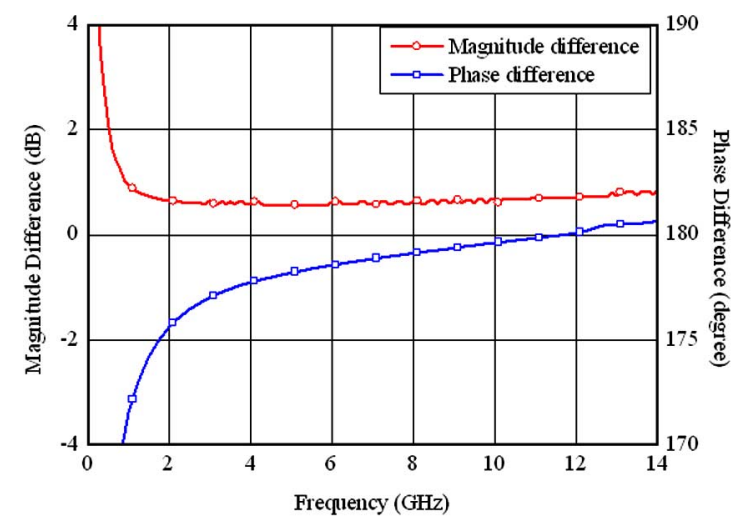

Fig. 2. Simulated magnitude and phase differences of the active balun.

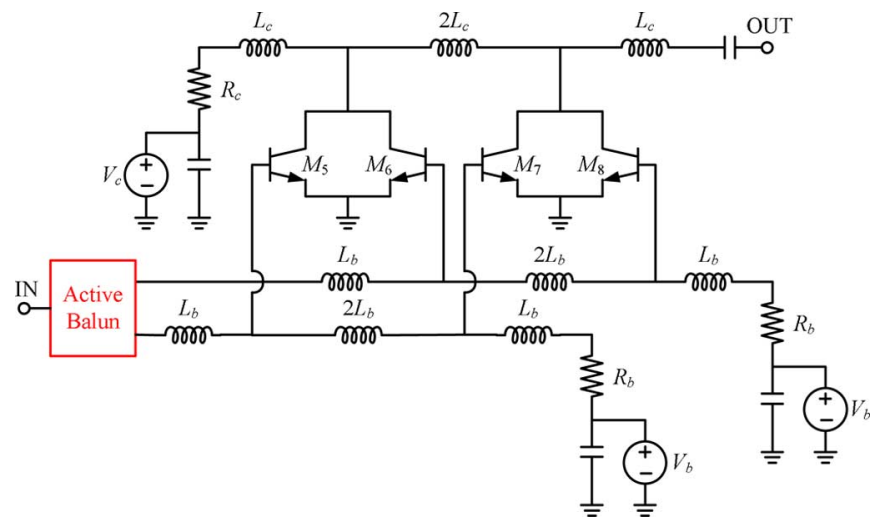

Fig. 3. Schematic of the distributed doubler.

The active balun consists of a differential pair, $M_{1}$ and $M_{2}$, for amplification, and the base of $M_{2}$ is connected to a bypass capacitor which provides a short circuit. The current source $M_{3}$ provides high impedance at $S_{1}$ to increase the common-mode rejection ratio (CMRR). The wideband input matching of the active balun is achieved by using a distributed topology that consists of two series inductors, the input equivalent capacitor of $M_{1}$ and a termination resistor. The inductive peaking is used at the output of the active balun to extend the operating frequency [7], [8]. To compensate the gain and the phase imbalances of the active balun, the $L_{3}$ and $L_{4}$ are selected to be 0.65 and $0.75 \mathrm{nH}$, respectively. Fig. 2 shows the simulated magnitude and phase imbalances of the active balun. Between 2 and $10 \mathrm{GHz}$, the magnitude difference is smaller than $1 \mathrm{~dB}$ and phase difference is between $175^{\circ}$ and $180^{\circ}$. This active balun can provide a good single-to-differential function for the balanced doubler.

The balanced distributed doubler consists of a reduced size rat-race coupler and two identical distributed doublers was proposed in a chip size of $1.5 \mathrm{~mm}^{2}$ [3]. In order to reduce the chip size of the doubler, the balanced distributed doubler which is composed with two base lines and a sharing collector line is proposed, as shown in Fig. 3. Two transistor pairs are selected for this doubler, and each transistor pair has differential input at base terminals and the collectors of are connected together. The base line is designed with $50 \Omega$ characteristic impedance for impedance matching. In addition to the impedance matching, a higher cut-off frequency of the collector line is required.

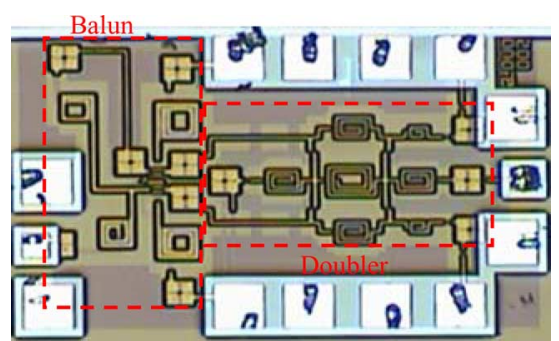

Fig. 4. Chip photo of the balanced distributed doubler.

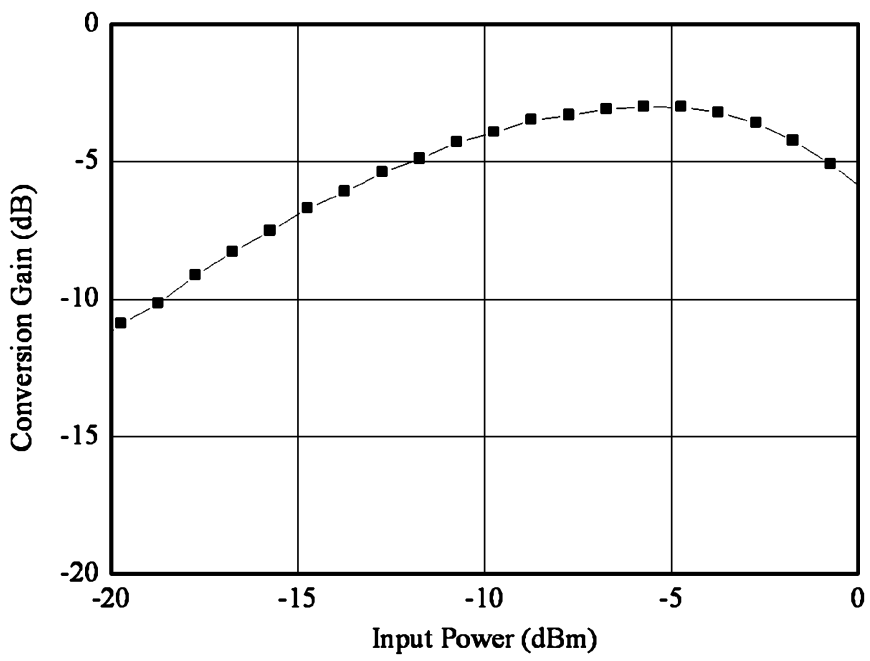

Fig. 5. Measured conversion gain versus input power at $4.5 \mathrm{GHz}$ input frequency.

Smaller inductors of the collector line result in lower characteristic impedance and higher cut-off frequency. The $35 \Omega$ collector line is selected in this design for compromising the impedance matching and operation bandwidth. The differential outputs of the active balun are connected to the two base lines of the distributed doubler to form the complete balanced distributed doubler. Fig. 4 shows the chip photo of the doubler, and the chip size of $1.1 \mathrm{~mm} \times 0.7 \mathrm{~mm}$.

\section{MEASUREMENTS}

The chip was measured using on-wafer probing. The transistors of the distributed doubler are biased near the pinch-off region. Fig. 5 shows the measured result of the conversion gain versus input power at input frequency of $4.5 \mathrm{GHz}$. It has maximum conversion gain of $-3 \mathrm{~dB}$ at $-7 \mathrm{dBm}$ input power. The conversion gain and fundamental rejection versus input frequency at $-7 \mathrm{dBm}$ input power are shown in Fig. 6 . The measured conversion gain is $-3--8 \mathrm{~dB}$ and the fundamental rejection is better than $23 \mathrm{~dB}$ for the output frequency between 4 to $18 \mathrm{GHz}$. The transistors of the active balun are biased at $1.65 \mathrm{~V} V_{b}$ and $3 \mathrm{~V} V_{c}$, and the power consumption is $52 \mathrm{~mW}$. The transistors of the doubler are all biased at $0.86 \mathrm{~V} V_{b}$ and $2 \mathrm{~V} V_{c}$, and this distributed doubler only consumes $8 \mathrm{~mW} \mathrm{dc}$ power.

Table I lists the comparison of the reported broadband active frequency doublers. This SiGe balanced distributed doubler has broadband characteristics with a good fundamental rejection 
TABLE I

COMPARISON OF THE RECENTLY REPORTED BROADBAND ACTIVE FREQUENCY DOUBLERS

\begin{tabular}{|c|c|c|c|c|c|c|c|c|c|}
\hline Reference & $\begin{array}{c}\text { Process } \\
\mathrm{f}_{\mathrm{t}} / \mathrm{f}_{\max }(\mathrm{GHz}) \\
\end{array}$ & Design topology & $\begin{array}{c}\text { Output } \\
\text { frequency }(\mathrm{GHz})\end{array}$ & $\begin{array}{c}\text { Conversion } \\
\text { gain }(\mathrm{dB})\end{array}$ & $\begin{array}{l}\text { Fundamental } \\
\text { rejection }(\mathrm{dB})\end{array}$ & $\begin{array}{l}\text { Input power } \\
(\mathrm{dBm})\end{array}$ & $\begin{array}{l}\text { DC consumption } \\
(\mathrm{mW})\end{array}$ & FOM & $\begin{array}{c}\text { Chip area } \\
\left(\mathrm{mm}^{2}\right)\end{array}$ \\
\hline [1] & $\begin{array}{c}\text { GaAs HEMT } \\
81 / 120\end{array}$ & $\begin{array}{l}\text { Distributed topology } \\
\text { with high-pass drain } \\
\text { line }\end{array}$ & $22 \sim 42$ & $-10 \sim-2$ & $>13$ & 13 & - & 4.67 & $2 \times 1$ \\
\hline [2] & $\begin{array}{c}\text { CMOS } \\
70 / 58\end{array}$ & $\begin{array}{l}\text { Distributed topology } \\
\text { with high-pass drain } \\
\text { line }\end{array}$ & $14 \sim 23$ & $-14 \sim-12$ & $>22$ & 5 & 13.5 & 11.08 & $0.54 \times 0.38$ \\
\hline [3] & $\begin{array}{c}\text { GaAs HEMT } \\
81 / 120\end{array}$ & $\begin{array}{c}\text { Balanced distributed } \\
\text { topology }\end{array}$ & $30 \sim 50$ & $-6 \sim-3$ & $>9$ & 10 & 132 & 7.24 & $1.5 \times 1$ \\
\hline [4] & $\begin{array}{l}\text { InGaP HBT } \\
60 / 75\end{array}$ & Balanced topology & $14 \sim 24$ & $6 \sim 10$ & $>22$ & -3 & 200 & 13.67 & $0.6 \times 0.7$ \\
\hline [5] & $\begin{array}{l}\text { SiGe bipolar } \\
85 / 128\end{array}$ & Gilbert-cell topology & $18 \sim 42$ & $0 \sim 8.6$ & $>7$ & -12 & 185 & 0.52 & $0.55 \times 0.45$ \\
\hline [6] & $\begin{array}{c}\text { InP DHBT } \\
100 / 170\end{array}$ & Gilbert-cell topology & $\mathrm{de} \sim 86$ & $-6 \sim-3$ & $>27$ & -8 & 730 & 14.73 & $1.4 \times 1.6$ \\
\hline $\begin{array}{l}\text { This } \\
\text { work }\end{array}$ & $\begin{array}{c}\text { SiGe BiCMOS } \\
70 / 57\end{array}$ & $\begin{array}{l}\text { Balanced distributed } \\
\text { topology with sharing } \\
\text { collector line }\end{array}$ & $4 \sim 18$ & $-8 \sim-3$ & $>23$ & -7 & 60 & 14.19 & $1.1 \times 0.7$ \\
\hline
\end{tabular}

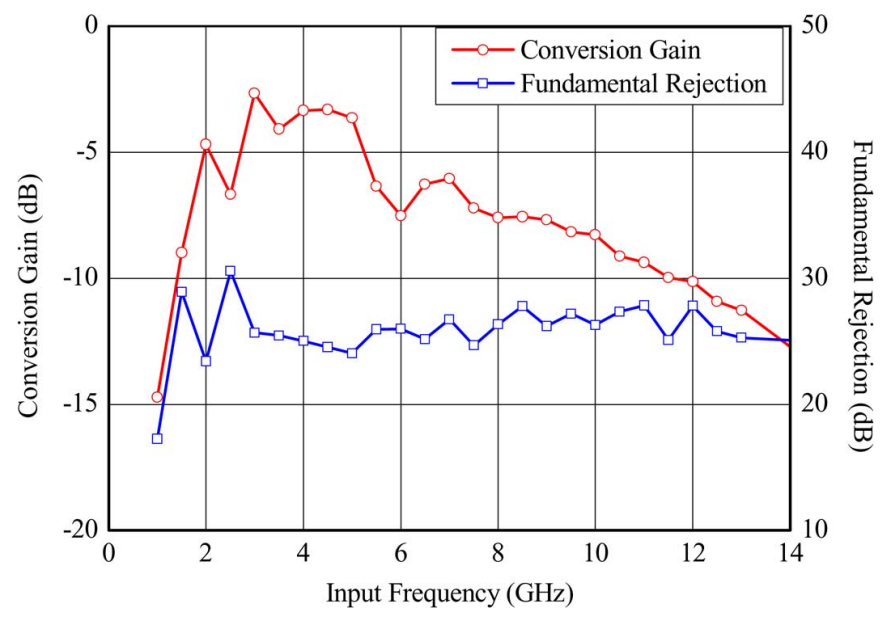

Fig. 6. Measured conversion gain and fundamental rejection versus frequency at input power of $-7 \mathrm{dBm}$.

under a lower dc power consumption compared with other balanced frequency doublers. A figure of merit

$$
\mathrm{FOM}=\left[10 \log \left(\frac{100 \times P_{\text {out }, 2 \mathrm{nd}}}{P_{\mathrm{in}, 1 \mathrm{st}}+P_{\mathrm{dc}}}\right)+\mathrm{FR}\right] \times \mathrm{BW}
$$

is defined for frequency doublers, where $P_{\text {out }, 2 n d}$ is the second harmonic output power, $P_{\mathrm{in}, 1 \mathrm{st}}$ is the input power, $P_{\mathrm{dc}}$ is the dc consumption, FR is fundamental rejection and $\mathrm{BW}$ is $3 \mathrm{~dB}$ fractional bandwidth. This broadband doubler has a good FOM which is comparable to that of the InP DHBT doubler [6].

\section{CONCLUSION}

A broadband balanced distributed doubler using $0.35 \mu \mathrm{m}$ SiGe BiCMOS process has been developed. The sharing collector line technique is proposed to minimize the chip size.
This doubler conversion gain is better than $-8 \mathrm{~dB}$ and the fundamental rejection is better than $23 \mathrm{~dB}$ from 4 to $18 \mathrm{GHz}$. The dc power consumption is $60 \mathrm{~mW}$, and the chip size is $1.1 \times 0.7 \mathrm{~mm}^{2}$.

\section{ACKNOWLEDGMENT}

The authors would like to thank Dr. H. Wang and Dr. C.-S. Lin, National Taiwan University, Taiwan, for their valuable suggestions.

\section{REFERENCES}

[1] Y. L. Tang, P. Y. Chen, and H. Wang, "A broadband pHEMT MMIC distributed doubler using high-pass drain line topology," IEEE Microw. Wireless Compon. Lett., vol. 14, no. 5, pp. 201-203, May 2004.

[2] K. Y. Lin, J. Y. Huang, J. L. Kuo, C. S. Lin, and H. Wang, "A 14-23 $\mathrm{GHz}$ CMOS MMIC distributed doubler with a 22-dB fundamental rejection," in IEEE MTT-S Int. Dig., Jun. 2008, pp. 1477-1480.

[3] K. L. Deng and H. Wang, "A miniature broad-band pHEMT MMIC balanced distributed doubler," IEEE Trans. Microw. Theory Tech., vol. 51, no. 4, pp. 1257-1261, Apr. 2003.

[4] D. W. Kang, D. H. Baek, S. H. Jeon, J. W. Park, and S. Hong, "A miniaturized K-band balanced frequency doubler using InGaP HBT technology," in IEEE MTT-S Int. Dig., Jun. 2003, pp. 107-110.

[5] S. Hackl and J. Böck, "42 GHz active frequency doubler in SiGe bipolar technology," in Proc. Int. Conf. Microw. Technol., Aug. 2002, pp. 54-47.

[6] F. Jorge, M. Riet, and J. Godin, "A DC-100 GHz frequency doubler in InP DHBT technology," in IEEE MTT-S Int. Dig., Jun. 2004, pp. 167-170.

[7] B. Razavi, "Prospects of CMOS technology for high-speed optical communication circuits," IEEE J. Solid-State Circuits, vol. 37, no. 9, pp. $1135-1145$, Sep. 2002.

[8] S. Shekhar, J. S. Walling, and D. J. Allstot, "Bandwidth extension techniques for CMOS amplifiers," IEEE J. Solid-State Circuits, vol. 41, no. 11, pp. 2424-2439, Nov. 2006. 